\title{
Mexico: A Revolution in Art, 1910-1940
}

\author{
Cintia Velázquez Marroni
}

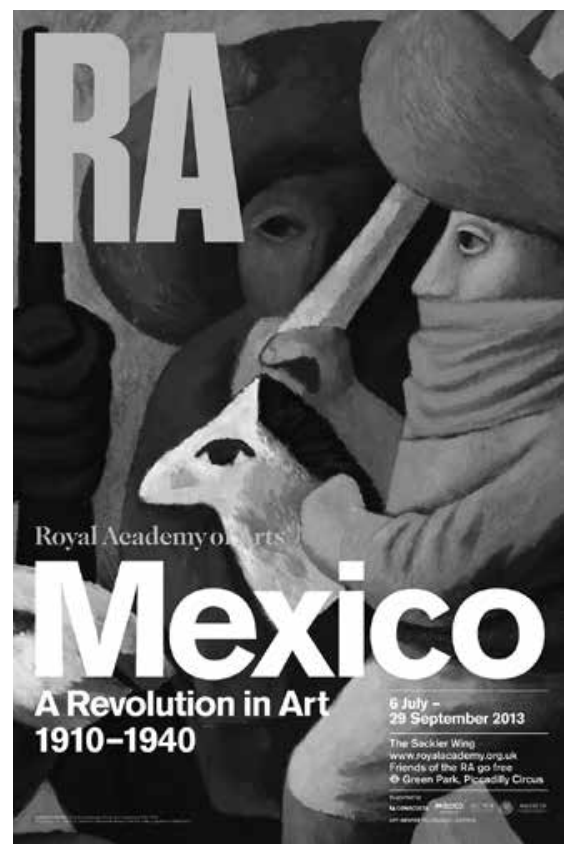

FIGURA 1. Cartel de la exposición. La pintura que se muestra en el fondo es de José Chávez Morado (Carnaval en Huejotzingo, 1939, colección del Phoenix Art Museum), una de las obras que figuraron en la exposición (Fotografía: Anon. 1939; cortesía: RA).

\section{L}

a Royal Academy of Arts de Londres (RA, Academia Real de las Artes) presentó del 6 de julio al 29 de septiembre de 2013 Mexico: A Revolution in Art, 1910-1940 (México: una revolución en el arte, 1910-1940, en adelante, Mexico...), exposición temporal curada por el doctor Adrian Locke, especialista en arte latinoamericano por la Universidad de Essex, Inglaterra, y curador de la RA, distribuida a lo largo de cuatro salas, con 120 obras (esencialmente, pinturas y fotografías) de artistas mexicanos y extranjeros activos en el territorio nacional entre las décadas señaladas.

La exposición generó opiniones encontradas, según se puede documentar en las reseñas publicadas en distintos medios ingleses, como The Guardian (Cumming 2013; Jones 2013), London Evening Standard (Sewell 2013), The Telegraph (Smart 2013) y The Independent (Darwent 2013). Al tratarse de un tema tan relevante para el país, la presente reseña se realizó con la finalidad, primero, de dar a conocer esta exhibición en el medio mexicano, y segundo, de evaluar - a partir no sólo de su visita sino también del diálogo entablado con el curador, en agosto de 2013 - su propuesta museológica. Se ha procurado proveer al lector de diversos elementos para conocer algunas de las complejidades generadas por la muestra, y a la vez nutrir el debate sobre la brecha -a menudo infranqueable - entre los presupuestos curatoriales, su implementación física y los procesos interpretativos del visitante.

Mexico... se ubicó en el tercer piso de la Sackler Wing of Galleries (las Galerías Sackler), un área relativamente pequeña $\left(323 \mathrm{~m}^{2}\right)$ dentro del amplio edificio de la RA, Ilamado Burlington House, una mansión del siglo XVII que se ha remodelado y ampliado desde entonces. ${ }^{1}$ Dos de las mencionadas reseñas hacían una crítica similar a la que aquí insinúo: el que una exposición dedicada a uno de los periodos más ricos de la historia moderna del arte se confinara a un espacio tan reducido.

\footnotetext{
${ }^{1}$ Se intentó gestionar el uso de imágenes para ilustrar la presente reseña, pero no fue posible obtenerlas debido a que, según se me explicó, una vez terminada la exposición, la RA no tiene derecho sobre ellas. Hasta marzo de 2014 estaban disponibles algunas imágenes y un video en la página de la RA (2013), pero fueron retirados a partir de la renovación del sitio. El catálogo aún está en venta en el sitio de la RA. Hay algunas imágenes disponibles en las referencias hemerográficas.
} 
Otro de los puntos en el que coincidían las reseñas —el más criticado de la exposición— era la falta de obras representativas del muralismo mexicano. El argumento esbozado estribaba, en resumidas cuentas, en que era inconcebible una muestra de arte sobre la Revolución mexicana que no abordara las contribuciones murales de Rivera, Orozco y Siqueiros, y que la inclusión en ella de artistas extranjeros era, por decir lo menos, irrelevante.

En efecto, Mexico... no se montó en las salas principales de la RA, que entonces albergaban Summer Exhibition; incluso podría decirse que la diferencia espacial establecida entre una y otra muestra fue sintomática de las prioridades que la RA dio a cada exposición. En efecto, la que aquí se examina no se concentró en los "tres grandes" - tampoco en Kahlo, de lo cual había expectativa, ciertamente- y mucho menos en la faceta mural de su trabajo; por el contrario, se remitió a obra de caballete, además de que incluyó fotografías de forma prominente. Por si fuera poco, no se limitó a artistas mexicanos, sino que incorporó una buena proporción de extranjeros. En suma, para algunos críticos, Mexico... fue una muestra que no cumplió con las expectativas. Cabe entonces preguntarse por las razones de esto: ¿por qué fue tan diferente de lo que se esperaba?, ¿por qué no se expuso más obra de artistas representativos del muralismo? y ¿por qué se hizo de esta manera?

La entrevista con el curador, Adrian Locke, me permitió hacer estas preguntas y dialogar sobre las decisiones que se tomaron al respecto. Locke manifestó su deseo de hacer una exposición que en primer lugar, justamente, no se centrara en los muralistas y dirigiera la perspectiva hacia otras soluciones plásticas de la época. El curador trabajó con base en el supuesto de que en el Reino Unido hay un gran desconocimiento sobre México y su arte, y que la muestra debía contribuir no sólo a subsanar esa carencia de información sino a ampliar las maneras de mirar a México, a menudo restringidas a visiones "tropicalistas" o folclóricas.

En segundo lugar, Locke diseñó un argumento curatorial complejo, en el que se relacionan diversos soportes artísticos: óleo, acuarela, fotografía, impresos y literatura —si bien ésta no estuvo presente en la exposición y únicamente quedó plasmada en el catálogo (Locke 2013)_, con interacciones y relaciones tanto profesionales como personales entre artistas de diversos países en un contexto social de gran efervescencia. La exposición, más que ceñirse a un artista, un grupo o una tipología de obra, aspiraba a insinuar las dinámicas de intercambio que se establecieron entre artistas en el periodo comprendido y el efecto que esto generó en la producción estética de entonces.

Finalmente, Locke también explicó su postura respecto del montaje y las decisiones museográficas. Se optó por minimizar los recursos interpretativos, entre ellos el cedulario, y privilegiar la exhibición de las obras en sí. Para Locke, las obras debían contar la historia, y tanto el soporte museográfico como los recursos de interpreta- ción debían ser neutros, para producir un encuentro más directo entre aquéllas y el visitante.

¿Pero qué sucede con los visitantes? ¿Los presupuestos curatoriales se corresponden con las dinámicas de visita? He ahí la cuestión: no lo sabemos. Manifesté a la RA mi deseo de hacer un breve estudio de público con el objeto de tener una comprensión más integral del círculo interpretativo de la exposición, pero no fue posible. Al parecer, la RA es una institución regulada en sus prácticas operativas y, según me informaron, si bien realiza sus propios estudios de público, los reservó para su publicación en el sitio de internet The Art Newspaper en abril de 2014. ${ }^{2}$ Por ello, las reflexiones que he venido presentando, y en las que ahondo enseguida, parten de mi experiencia personal como visitante, no sin señalar que mi visión es la de una especialista en museología, no en arte.

Al visitar la exposición, uno de los primeros aspectos que me sorprendió fue su dimensión; en efecto, esperaba más. Y, sin embargo, ciento veinte obras distribuidas en cuatro salas cautivaron mi atención durante cerca de cuatro horas. La incomodidad de recorrer la primera sala, "Mexico in Flames, 1910-1920" ("México en Ilamas"), pequeña y atiborrada de visitantes, dio paso en la segunda, "The Return of the Native, 1921-1928" ("El regreso de lo nativo"), a una sensación de color, amplitud y diversidad. Las salas tercera, "The Clash of Sun and Shadow, 1929-1934" ("El choque del sol y su sombra"), y cuarta, "Unadulterated Artistic Creation, 1935-1940" ("La creación artística pura"), me capturaron por la alternancia de pintores y fotógrafos.

Recuerdo que las salas 1 y 2 me parecieron muy distintas: la primera tenía demasiados formatos en un espacio breve: una litografía, un exvoto, dieciséis fotografías, dos óleos y ocho impresos, mientras que la segunda destacaba, en un espacio más amplio, la prominencia de óleos - junto con una sección fotográfica- donde abundaba el color, anunciado ya desde el tiro visual que se tenía desde la sala inicial: un gran óleo con tonos naranjas y verdes de Diego Rivera que no había visto antes (Baile en Tehuantepec, 1928, colección privada). Muy distintas, asimismo, en tanto que consideré mucho menos claro el sentido de la primera; me confundió, por ejemplo, encontrar el óleo de Saturnino Herrán (Mujer de Tehuantepec, 1914, INBA-Museo de Aguascalientes) al lado de las crudas fotografías de Walter $\mathrm{H}$. Horne sobre ejecuciones públicas en el norte de México, datadas para 1916 (pertenecientes al Getty Research Institute). Por el contrario, en la segunda sala me quedó claro que había una gran diversidad de maneras en que los artistas, tanto nacionales como extranjeros, intentaban abordar el tema de la iden-

\footnotetext{
${ }^{2}$ Los resultados están disponibles en el sitio mencionado pero debe pagarse una cuota para su consulta. Cabe mencionar, además, que los resultados son más bien de tipo cuantitativo (estadísticas de visita a diferentes exposiciones) y no cualitativos.
} 
tidad, ya desde visiones más "antropomórficas", como las Mujeres mayas, de Roberto Montenegro (1926, MOMA), ya menos literalmente, como Mandolinas y piñas, de Rufino Tamayo (1930, The Phillips Collection), pasando por las fotografías de Tina Modotti y Edward Weston.

Como visitante, disfruté conocer artistas de los cuales no sabía nada, como el estadounidense Marsden Hartley y los ingleses Leon Underwood y Edward Burra, cuyas acuarelas sobre México no se habían exhibido nunca antes, así como ver expuestos en el extranjero, más allá de "los tres grandes", otros autores mexicanos. También gocé el que Mexico... no se circunscribiera a Frida Kahlo (representada con un pequeño y poco conocido Autorretrato, 1938, Sotheby's) y que se mostraran obras de caballete de Orozco (La trinchera, 1931, MOMA), Siqueiros (Zapata, 1931, Hirshhorn Museum) y Rivera (ya mencionada).

¿Qué tanto se satisficieron, en mi experiencia personal, las expectativas que su curador tenía para la exposición? Algunas sí y otras no: funcionó como un mosaico de distintas visiones e introdujo en la discusión nombres desconocidos o marginados frente a la prominencia de otros más famosos. La museografía fue limpia - definitivamente, sobria y sin "tropicalismos" - lo que, en efecto, me permitió observar la variedad, propuesta y riqueza de las obras. Sin embargo, por momentos me quedé con deseos de ver más claramente los vínculos entre los artistas, para entender las consecuencias que éstos tuvieron en la producción de la época; es de suponer, además, que visitantes con un mayor desconocimiento del tema tampoco hayan podido percibir este elemento tan importante del argumento expositivo.

Por el contrario, el catálogo (Locke 2013), que la crítica recibió bastante favorablemente, sí presenta de forma más efectiva esos vínculos, y, todavía más: quizás a la larga consolide los propósitos originales que el curador tenía para la exposición. En este sentido, cabe preguntarse si esto fue, entonces, un asunto específico de Mexico... o si más bien esta muestra nos remite, en turno, a grandes debates de la museología, como, por ejemplo, los límites de la exposición como medio de comunicación, las posturas curatoriales frente al tema de la interpretación o los procesos de recepción de los visitantes.

\section{Agradecimientos}

Agradezco al doctor Adrian Locke la entrevista y plática que sostuvimos a principios de agosto del 2013, funda- mental para escribir esta reseña; asimismo, a la RA, en especial a Johanna Bennett, del departamento de prensa, por el apoyo y las facilidades brindados para visitar la exposición.

\section{Referencias}

Cumming, Laura

2014 "Mexico: a Revolution in Art, 1910-1940 -Review", The Guardian/The Observer, 7 de julio de 2013, documento electrónico disponible en [http://www.theguardian.com/artanddesign/2013/jul/07/mexico-revolution-art-review-royal], consultado en febrero de 2014.

Darwent, Charles

2014 "Visual art review: Mexico: a Revolution in Art, 19101914 — so where is the writing on the wall?", The Independent, 6 de julio de 2013, documento electrónico disponible en [http://www.independent.co.uk/arts-entertainment/art/reviews/ visual-art-review-mexico-a-revolution-in-art-19101914--sowhere-is-the-writing-on-the-wall-8692562.html], consultado en febrero de 2014.

Jones, Jonathan 2014 "Royal Academy's Mexican Revolution misses the bigger picture", The Guardian, 9 de julio de 2013, documento electrónico disponible en [http://www.theguardian.com/artanddesign/2013/jul/09/royal-academy-mexico-revolutionart], consultado en febrero de 2014.

Locke, Adrian

2013 Mexico: a Revolution in Art, 1910-1940, catálogo de exposición, Londres, Harry N. Abrams/Royal Academy of Arts.

RA

2013, Royal Academy (RA), documento electrónico [página web], disponible en [http://www.royalacademy.org.uk], consultado en febrero de 2013.

Sewell, Brian

2014 "Mexico: a Revolution in Art, 1910-1940, Royal Academy-exhibition review", London Evening Standard, 11 de julio de 2013, documento electrónico disponible en [http://www.standard.co.uk/goingout/exhibitions/mexicoa-revolution-in-art-19101940-royal-academy--exhibitionreview-8702578.html], consultado en febrero de 2014.

Smart, Alastair

2014 "Mexico, at the Royal Academy", The Telegraph, 5 de julio de 2013, documento electrónico disponible en [http:// www.telegraph.co.uk/culture/art/art-reviews/10159653/ Mexico-at-the-Royal-Academy-review.html], consultado en febrero de 2014. 


\section{Resumen}

La reseña de Mexico: A Revolution in Art, 1910-1940, exposición de la Real Academia de las Artes (Londres, Reino Unido), que describe a grandes rasgos su contenido y a la vez evalúa sus contribuciones y problemáticas, se elaboró con base en la visita y análisis de la muestra, así como en la entrevista con su curador, el doctor Adrian Locke, realizada a principios de agosto de 2013.

\section{Palabras clave}

reseña; exposición; México; Revolución; arte; Real Academia de las Artes; Reino Unido

Título en inglés: Mexico: A Revolution in Art, 1910-1940

\section{Abstract}

This review of Mexico: A Revolution in Art, 1910-1940 (Royal Academy of Arts, London, United Kingdom) provides a general description of the exhibition contents, whilst making an assessment of its contributions and the issues at stake on this display, by both analyzing the exhibit as visitor and providing information from an interview with its curator Dr. Adrian Locke which took place in early August 2013.

\section{Key words}

review; exhibition; Mexico; Revolution: art; Royal Academy of Arts; United Kingdom

Postulado/Submitted 12.09.2013

Aceptado/Accepted 12.03.2014 